\title{
The Impacts of Discipline, Motivation and Leadership in Makassar Lantamal Vi Office - Indonesia
}

\author{
Dr. Jamil Thalib, SE, MS. \\ The lecturer of Economic Science College of Ujung Pandang Education, \\ Foundation - Makassar, South Sulawesi Province, in the Middle Part of Indonesia \\ Email: andipallawab@rocketmail.com
}

Doi:10.5901/ajis.2015.v4n2p117

\section{Abstract}

This research aims at analyzing the influence of discipline, motivation, and leadership towards the employees' performance at Makassar Lantamal VI office, and recognizing the factors affecting dominantly. This research was a survey study involving 266 State Government employee but only 73 employees were determined as the samples. Analysis approach was multiple linear regression analyses. The findings indicate that discipline, motivation and leadership influence positively the staffs' performance at Makassar Lantamal VI office. This is known from the significant value of partial regression coefficient of the $t$-test and the $f$ test that are $<$ the value of $(\alpha=0.5 \%)$ where the motivation factor is as the more effective factor. The conclusion states that discipline, motivation and leadership affect partially and simultaneously the staffs' performances of Makassar Lantamal VI office, but motivation factor influences more dominantly than that of the discipline, motivation and leadership do.

Keywords: Discipline, Motivation, Leadership, Employees' performance.

\section{Introdcution}

Public services from year to year undergo demand developments to the Government, in terms of the State Government Employees of Indonesia for being able to give the optimal services to the societies that are usually called 'primary services.' As the Nation employees and society servicers, the State Government Employees' responsibilities are demanded to offer services to societies. Public services are usually done by either central Government or Regency Government in which the societies' high demands of better services compel sorts of government institutions to push the development of the prime performances.

The implemented government's tasks and optimal building, the State Government employees are required to have higher disciplines either for themselves or for their jobs, but in fact, there are still many employees not discipline to be on time working. The risk of this indiscipline affects negatively the employees' performances. In the Government's rule, numbered 53/2010 of the State Government employees' disciplines on articles 2 and 3 about responsibility and prohibition have been constructed clearly that should be obeyed by every State Government employee.

Derived from the direct observation through phenomena in the discipline application, it is found that many employees at 'Makassar Lantamal VI office' (= Makassar Main Naval Base VI Office) have problems of the office attendance, they are late to be in the office, absent without any reasons, conduct other activities outside of the office that cause many works to be late.

To produce the expected performance result and to reach the organization purposes, a motivation needs to be available in order that the employees can work well. The motivation comprehensive, either existing in the employee's body or coming from environment can help develop performances. The manager or leader needs to lead the motivation by creating the organization condition through forming the working culture or organization culture in order that the employees feel to be motivated for working hard in obtaining high performances.

The leadership very affects the organization, successful or failure in conducting the duties to an organization and government implementation are influenced by the leader/manager and supported by adequate government organization capacities, and then the implementation of good government management can be obtained.

The leadership realization going on Makassar Lantamal VI office does not run smoothly as being expected. This can be seen from the less observation that is done by the leader/manager towards employees in every action when they are on duty that the employees feel free in working, and deleting their responsibility given to them. With respect to these descriptions, this research investigates the impact of discipline, motivation and leadership towards the employees' 
performances in Makassar Lantamal VI office.

\section{Literature Reviews}

These literature reviews are concerned with two main points, such as previous studies, and reviews of related literatures. The following are their descriptions displayed below respectively.

\subsection{Previous Studies}

Several previous studies were carried out by other researchers whose studies referred to the case studies of the motivation effect and disciplines towards workers' performances. The following were studies conducted by some researchers presented below correspondingly.

Etykawaty's research (2008) indicated the motivation influence and discipline on the penitentiary staffs' performances in Surakarta through quantitative descriptive research. Her research results showed that there was a positive motivation and discipline towards penitentiary staffs' performances in Surakarta prison. Whilst Harnowo's research (2008) also investigated the impact of discipline application and leaderships towards the performances of Wonogiri region employment board. This research exerted the explanatory study by analyzing the data via multiple regression linear. Its results indicated that the independent variable as the working discipline and leadership affected the performances of Wonogiri region employment board on the confident level of $95 \%$ ( $\alpha=0.05 \%$ ), and the discipline variable influenced more dominant towards the performances of Wonogiri region employment board.

Another study was done by Cecep, Dani (2009) concentrating on the impression of leaderships, motivation and communication toward the staffs' working spirit in the territory office of the National defense of West Java Province. His research results revealed that leaderships, motivation and communication brought about a positively significant impact via either partial or simultaneous towards staffs' working spirit in the territory office of the National defense of West Java Province.

\subsection{Reviews of Related Literatures}

This session reveals several sub-topics, such as (1) 'disciplines,' dealing with preventive discipline, corrective discipline, (2) 'motivation,' and (3) other subtopics. These three points are presented respectively as follows.

\subsubsection{Discipline}

Dessler (2008) states that 'discipline' is a procedure correcting and punishing a subordinate because a rule or procedure has been violated. Related to the work, it can be said the working discipline is an attitude to appreciate, respect, obey, and being loyal on valid rules, either written rules or oral rules, and being able to do those rules, and when the organization members violate the given duty and authority, they do not avoid receiving the punishment.

Furthermore, Davis (2004) states that discipline is an action or a management behavior demanding the need fulfillment towards organization standard. Whilst Hasibuan (2005) states that discipline is a regulation condition where people included in the organization discipline obey the available rules cheerfully. He proceeds stating that some factors affect the worker's disciplines namely, the purposes and abilities, leaders' model, remuneration, justice, built-in control, law risk, firmness, and human relationship. All these factors affect the discipline application in an organization.

The employees' discipline behavior is a thing that does not appear by itself but it needs to be formed. Therefore, forming the working discipline can be done through two ways, firstly via preventive discipline. The preventive discipline is an action done for pushing workers to obey the norms and rules in order that the corruptions do not happen. Its purpose is to shove self-discipline of among the employees. Secondly, through corrective discipline for handling the violation towards rules, and attempting to keep away from further violations. The corrective activity is often a kind of punishment form called disciplinary action.

\subsubsection{Motivation}

Motivation is an activity distributing and taking care human behavior. It is an important subject for manager/leader since the manager/leader works through other people. The manager/leader needs to understand other people having certain 
behavior in order to affected their work according to what is needed by the organization. Motivation is also a confusing subject because the motive cannot be observed or measured directly but it must be concluded from the real people' behavior.

Motivation not only is one of factors influencing a person's prestige level, but the other two factors of individual ability and behavior comprehension are needed as well to obtain high prestige that is called the perception role. Motivation, ability, and perception role are mutually related each other. Thus, if one of the factors is low, the prestige level is also low even if the other factors are high. There are several terms used to mention 'motivation or motive, and among of them are need, urge, wish, and drive, in which motivation is used. Motivation is an expertness in directing employees and organization work successfully to gain employees' desire and simultaneously the organization purpose is reached.

People are enthusiastic to work for fulfilling their needs through either conscious or unconscious needs, and so are they for obtaining physical and mental needs. Brantas (2009) states that people are eager to work because of the desire to live. This means, they wish to be alive is the primary need of everybody. Human beings work for having food to continue being able to be alive. Further, human beings work because of the desire for possession. This implies that the desire to have something is the secondary human's need, and this is one of causes why people want to work. Another desire is that human beings work because of the desire for power. This means that the desire to have the authority is a wish of one step over the desire for possession that pushes people want to work. The last one is the desire for recognition. This indicates that the desire for being acknowledged is the last need that also moves forward people to work.

\subsubsection{Other Topics}

In an organization, varied views of motivation can be discussed. The various motivations presented in this research are closely connected to the organization in terms of (1) Traditional model, (2) Human beings' relationship model, (3) Theories of motivation, (4) The contents of theory, (5) Frederick Herzberg's two factor theories (6) McClelland's motivation theories (7) Expectancy, (8) Motivation devices, (9) Motivation types, and (10) Leaderships. These ten points are displayed respectively below.

\subsubsection{Traditional Model}

Frederick Taylor (1930) states that traditional model and scientific management are determined by a manager who determines how works must be done and the incentive wage system is used for motivating the workers. The more production is obtained, the more incomes are possessed. This model regards that workers basically are lazy and they can only be motivated by giving them money as the appreciation. In many situations, this approach is effective enough. In reference to increasing the efficiency, the needed workers can be decreased. The manager further reduces the amount of the wages, the termination of employment becomes common, and the workers seek the working guarantee than that of the increasing small and contemporary wages.

\subsubsection{Human Beings Relationship Model}

Many management practitioners feel that the traditional approach is not adequate. Mayo, Elto, et al.,(1933) find that the staffs of social contact are obviously also important, in which the tiredness and tasks as the repeated activities are motivation reduction factors. They are sure that the manager can motivate his/her employees via fulfilling their social needs, and making them being useful and important. Consequently, the employees are given varied freedoms to make their own decisions in their works. The great paid attention is directed to the informal organization working groups. There should be much more information and organization operations the manager provides for the employees.

\subsubsection{Theories of Motivation}

Among authors of management categorize motivation theories into three groups, namely prescriptive, content, and process theories. The prescriptive theories reveal how the employees' motivation is, and the content theories concentrate on the query what is motivation?, whilst the process theories deal with how is the behavior begun and implemented?, or to explain the aspect 'how motivation is' (Brantas, 2009). 


\subsubsection{The Contents of Theories}

The content theories of motivation focus the attention on the question. What makes causes of behavior occur and stop? The answers of this query concentrate on: (1) Needs and motives press on and reinforce employees to do activities, and (2) the liaisons among employees with the external factors suggest, cause, push and influence them conducting the activities. This theory emphasizes the urgency of understanding on the individual internal factors, needs, or motives that make them choose activities, ways and certain behavior to satisfy their needs. The external factors like wages/salaries, work condition, work relationship, and trade's policy of the rank promotion, authority delegation, etc., reveal appreciations of usefulness to obtain the positive employees' behavior in attempting to gain the organization purposes.

\subsubsection{Herzberg's Two Factor Theories}

These theories state that the ideal motivation exciting trades is an opportunity to carry out the tasks that need experts and develop capability. Based on Herzberg's (1966) research results, three important cases that should be paid much attention to motivate employees, namely, (1) something shoving/pushing the employees is the challenging work covering the prestige feeling, responsibility, being able to enjoy the work, and the recognition of all of them, (2) Things making the employees disappointed are the unimportant working factors towards working rules, resting times, information, positions, authority, salaries/wages, and intensive, and (3) the employees are dissatisfied if the change to have prestige is limited. They become sensitive on their environment and begin to seek fault.

Furthermore, Herzberg (1966) thinks that people conducting jobs are affected by two factors as the needs, for instances, (1) maintenance factors. These factors relate to the truth human beings who want to have physical peace. This need happens continuously and returns to the zero point after being fulfilled. For example, the hungry people will eat then being hungry and then will eat again, etc. These factors refer to the cases of salaries/wages, physical working condition, job certainty, exciting supervision, official cars, official houses, and other intensives. The absent of these facilities can make the dissatisfaction impacts that cause the employees' truancy happens. As a result, these factors need paying attention by the manager in order that the employees' working satisfaction and eagerness can be increased, (2) Motivation factors are concerned with someone's psychological needs dealing with perfective feeling in doing the jobs. They refer to the individual appreciation which is directly related to the jobs. The hygienic concept is also called 'factor two theories' dealing with (a) achievement, (b) recognition, (c) the work itself, (d) responsibility, and (e) advancement.

In line with the above theories, the first factor displays someone's relationship with what s/he does to the job content of the tasks. The second factor is the hygienic concept dealing with (a) company policy and administration, (b) supervisor quality, (c) interpersonal relation, (d) working condition, and (e) salaries/wages. From these theories, the understanding rises that the job plans of the two factors must be attempted in order to the maintenance and motivation factors can be fulfilled.

\subsubsection{McClelland's Motivation Theories}

Another research of motivation done by McClelland (1961) recommends that there are three types of needs, namely: (1) achievement needs are for prestige needs as the reflection motivation of problem solving responsibility. An employee having a high participant need, tends to have a risk. The need for being prestige is the need to carry out a job much better than that before, s/he is always eager to reach higher prestige, (2) need for affiliation, namely, the need for social communication as the motivation to interact to other persons, existing together other persons, or s/he does not conduct anything that harms other persons, (3) need for power, namely the need of authority as the sort of motivation reflection for obtaining the authority and for having other persons' impact. This McClelland's achievement motivation theory claims that employees have a potential energy reserve. How the energy is released and exerted, depending on someone's motivation power and condition, and the available change. The energy is to be implemented by the employees because they are motivated by motive, expectation and incentive. (1) The motive is an eagerness stimulation and movement power of someone's job in which each motive has a certain aim that is to be gained, (2) The expectancy is a chance given that happens because of the behavior of reaching the goal, and (3) The incentive is concerned with the employees stimulation by bestowing rewards to them whose prestige is above standard prestige. Thus, the employees' working spirit is to increase because people are generally happy to receive good things (Brantas, 2009).

The reasons impelling people to do things are caused by needs that must be fulfilled. Hasibuan (2006) divides the human beings' needs into three needs such as: (1) Needs for achievement as the movement power motivate someone's 
working spirit. Therefore, the achievement needs push people to develop creativities and conduct their all capabilities and energy for reaching the maximal working prestige, the employees who are enthusiasts to gain high working prestige, will have high incomes that can support their needs if they are given chances, (2) Needs for Power as a movement power motivates employees' working spirit. The needs for power will push all capabilities for obtaining authority and better working position. People's ego wants to dominate other people that will produce rival. This rival should be built honestly by the manager in motivating her/his employees so as to working hard (Brantas, 2009), and (3) The needs for affiliation also become a movement power that motivates someone's working spirit. They stimulate the employees' eagerness because everybody needs the following cases: (a) The sense of belonging refers to the needs of feeling accepted by other people in the environment where they live and work, (b) The sense of important, deals with the needs of respected feeling since everybody feels himself very important, (c) The sense of achievement is concerned with the needs of progressive feeling and is not failing, and (d) The sense of participation relates to the needs of involving in any activities.

In motivating employees, the leaders should provide devices, create attractive jobs and give a promotion chance. Consequently, the employees might increase their working spirit for gaining the prestige needs, affiliation and the power they wish as the movement power towards motivating all their own potentials they have. This theory states that someone has needs relating to the place and environment condition where s/he works that can be measured via the following indicators: (a) justice and appropriate salaries/wages, (b) the chance for development, (c) individual recognition, (d) working safety, (e) good working place, (f) group acceptance, (g) plain treatment, and (h) prestige recognition (Brantas,2009).

\subsubsection{Expectancy}

The expectancy is a given opportunity occurring because of the behavior in obtaining the goals. Generally, the expectancy can be meant as someone's temporary belief that by a certain acting is to be followed by the next result or acting. In this concept, this expectancy can be measured zero, but it can also be measured as one value if we are really sure that its result is available. This theory simply states that someone' expectancy in an organization depends on his/her expectancy. S/he is to have high motivations for being high prestige in the organization if s/he believes that from his/her prestige, s/he can expect more big rewards/compensation, and vice-versa, someone does not have any expectancy that his/her prestige is to be respected highly, s/he does not attempt to increase her/his prestige.

In line with the above descriptions, Gibson, et al., (2007) illustrates the first result and the second result of the expectancy theory proposed by Vroom (1983) to test the equality of expectancy theory in predicting the employees' behavior. The first rank result of behavior is the result referring to the job application itself. The result covers products, shift workers' absences, and products quality. The second rank result deals with events (expectancy or punishment) which are perhaps caused by the the first rank result, like the goodness of salaries/wages increase, acceptance or rejection of group and promotion (Gibson, et al., 2007).

Vroom ((1983) suggests that an employee's beliefs about Instrumentality, Expectancy, and Valence interact psychologically to create a motivational force such that the employee acts in ways that bring pleasure and avoid pain. The following are their descriptions presented respectively below. Firstly, the instrumentality refers to the perception of employees as to whether they will obviously have what they desire even if it has been promised by a manager. Management must guarantee that promises of rewards are fulfilled and that employees are aware of that. Secondly, the valence refers to the emotional orientations people possess with respect to outcomes [rewards]. The depth of the want of an employee for extrinsic [money, promotion, time-off, benefits] or intrinsic [satisfaction] rewards). Management must discover what employees value, and Thirdly, the expectancy is concerned with employees have different expectations and levels of confidence about what they are capable of doing. Management must find out what resources, training, or supervision employees need.

\subsubsection{Motivation Devices}

The tools of motivation that can be provided for the employees are (1) incentive materials, namely, the motivation characterizes materials as the given reward prestige included the incentive materials such as salaries/wages, goods and things alike, and (2) incentive non- materials, for instance, the motivation refers to non-incentive materials, such as the accurate incomes, systematic training, objective promotion, guaranteed jobs, appreciation program, debt and credit service, and things alike. 


\subsubsection{Motivation Types}

Types of motivation consist of incentive positive that refers to a positive motivation. It means, when the employees can get the over average prestige, they are given reward. Whilst the incentive negative motivates the employees by punishment, it means that if the employees' prestige is less than the standard prestige, they are punished, except if their prestige is over average standard, they are not given anything.

In practice, both of the above motivations are often exerted in a trade. Positive and negative incentives must be according to the agreement. When the leader thinks that something is given as an incentive but the employee thinks it is not, the incentive usefulness will be useless. Gibson (2007) aims at that the organization performance depends of the individual performance. In other words, the individual performance is to contribute the organization performance, it means that the organizational membership performance either individual or group reveals power on the organization performance because her/his motivation is to affect the organization performance.

Several basic principles of modern management experts can be concluded as follows: (1) The management cannot be seen as a technical process strictly that refers to roles, procedures, and principles, (2) The management must be systematic, and the approach used must be considered carefully, (3) The organization is regarded as a whole, and the individual manager approach for supervision must be according to the condition, (4) Motivational approach resulting in workers commitment towards the organization purposes is very needed.

\subsubsection{Leaderships}

Stoner, F. and Gilbert, Jr. (1995) formulate the leadership definition is a process leading that affects the related job activities of the groups. This formulation has varied cases that can be explained in the details. A process will be going on if there is a power factor. By this power factor, the activities will be created to activate other elements particularly for people having tasks that have been described. The leadership takes place in every organization formally and nonformally.

Stoner, F. and Gilbert, Jr. (1995) state that there are four leadership implications such as: (1) the leadership involves other people. The people included in it are named the 'followers'. There have never been a leader without followers, it means that the leader never exists without the followers. (2) The power availability deals with the capability to use his/her impact to shift the employees' behavior. This power is based on various conditions, such as compelling, giving reward, giving authority, showing model and justice, and having expertness, (3) Being influenced employees. The employees will conduct something or have a certain behavior task which has been determined as a responsibility, and the follow-up on their leader's action and behavior, and (4) The value availability is concerned with the leader's individuality becoming the main model for the followers to be affected. The moral aspect colors the leader's value in which the followers are to learn to hear and act according to morality and ethic that belong to the leader.

\section{Research Methods}

This session dealt with (a) data collection Procedures, (b) Data Collection Techniques, (c) Data Analyses, and (d) Operational Definitions. The following were their descriptions presented respectively.

\subsection{Data Collection Procedures}

To have precise data, the researcher collected qualitative data and quantitative data, the primer data and the secondary data. The primer data were done in September to November, 2014 through survey, field observation, and interviews. These data were addicted, and classified, whilst the secondary data were conducted via two stages, namely: (1) the institution's sources of Makassar Lantamal VI office in which these data were reanalyzed according to the purposes of this study, and (2) the data from outside of the research areas were gathered to complete the secondary data obtained from stages before.

Regarding with the above data, the research queries were formulated as follows: Did working discipline, motivation and leadership affect the employees' performances at Makassar Lantamal VI office?" Another question was that: What did dominant factors influence the employees' performances at Makassar Lantamal VI office?" 


\subsection{Data Collection Techniques}

The techniques used in collecting data were interviews, questionnaires, and documentaries. The population of this research consisted of 266 employees of Makassar Lantamal office VI but only 73 of them were selected as the samples of this research. The analysis method employed was the qualitatively descriptive analysis and multiple regression analyses for recognizing the impact of the three independent variables namely $X_{1}$ (working discipline), $X_{2}$ (discipline) , and $\mathrm{X}_{3}$ (leadership) towards the dependent variables $\mathrm{Y}$ (the employees' performances at Makassar Lantamal office VI. To determine that there was a significant impression between the independent variable with respect to the dependent variable, the regression of coefficient statistical test was used.

\subsection{Data Analyses}

The analysis method employed was the qualitatively descriptive analysis and multiple regression analyses for recognizing the impact of the three independent variables namely $\mathbf{X}_{\mathbf{1}}$ (working discipline), $\mathbf{X}_{\mathbf{2}}$ (discipline), and $\mathbf{X}_{\mathbf{3}}$ (leadership) towards the dependent variables $Y$ (the employees' performances at Makassar Lantamal office VI). To determine that there was a significant impression between the independent variable with respect to the dependent variable, the regression of coefficient statistical test was used.
Where:
Y: Employees' performances
$\mathbf{X}_{\mathbf{1}}$ : Working discipline
$\mathbf{x}_{\mathbf{2}}$ : Motivation
$\mathbf{x}_{3}$ : Leadership
$\mathbf{b}_{0}$ : Constant
$\mathbf{b}_{1}$ : Coefficient regressions
$\mathbf{b}_{2}$ :Coefficient regressions
$\mathbf{b}_{3}$ :Coefficient regressions

$\mathbf{Y}=\mathbf{b}_{\mathbf{0}}+\mathbf{b}_{1} \mathbf{X}_{1}+\mathbf{b}_{2} \mathbf{X}_{2}+\mathbf{b}_{3} \mathbf{X}_{3}+e$

\subsection{Operational Definitions}

Based on the theoretical description related to the variables, the operational definitions were displayed as follows: (1) the working discipline $\left(\mathrm{X}_{1}\right)$ was the management activity to carry out the organizational standards. The discipline was someone's awareness and willingness to obey all organizational rules and valid social norms, (2) Motivation $\left(\mathrm{X}_{2}\right)$ was an energy power making someone to use her/his capability to conduct various activities for obtaining the planned goals, (3) Leadership $\left(\mathrm{X}_{3}\right)$ referred to the Chief's way of Makassar Lantamal VI office as the leader for affecting and leading the employees to conduct their tasks and responsibilities, (4) The employees' performances ( $\mathrm{Y}$ ) were the process and employees' work in doing their tasks and responsibilities based of their competence demanded that they showed in their work, and determined goals they obtained.

\section{Findings and Discussion}

The findings of this research concentrate on (1) employees' performances, (2) discipline, (3) motivation, (4) leaderships, and (5) variable impact analyses. The following are their descriptions displayed respectively.

\subsection{Employees' Performances}

The employees' performances are the processes and working results in doing their tasks and responsibilities based on their demanded competence through their work and goals that have been determined before. The employees' respond results on their performance indicator are presented in the following table. 
Table 1. The answer recapitulations of the employees' performances

\begin{tabular}{c|c|c|c}
\hline No & Category & Frequency & Percentage \\
\hline 1 & Very agree & 10 & 13,7 \\
2 & Agree & 29 & 39.7 \\
3 & Abstain & 17 & 23.3 \\
4 & Disagree & 11 & 15.1 \\
5 & Very disagree & 6 & 8.2 \\
& Total & 73 & 100 \\
\hline
\end{tabular}

Sources: Questionnaire result data

The respondent's highest respect towards the employees' performances on the category 'agree' is $39.7 \%$ followed by the abstain category $23.3 \%$, and the lowest level on the category 'very disagree' is $8.2 \%$.

\subsection{Discipline}

The working discipline $\left(\mathrm{X}_{1}\right)$ is a management activity to conduct the organizational standards. The discipline is someone's awareness and readiness to obey all organizational rules and valid social norms. The respondents' answers on the discipline indicators are presented in the following table.

Table 2. The answer recapitulations of the employees' disciplines

\begin{tabular}{c|c|c|c}
\hline No & Category & Frequency & Percentage \\
\hline 1 & Very agree & 15 & 20.6 \\
2 & Agree & 32 & 45.2 \\
3 & Abstain & 12 & 16.4 \\
4 & Disagree & 7 & 9.6 \\
5 & Very disagree & 6 & 8.2 \\
& Total & 73 & 100 \\
\hline
\end{tabular}

Sources: Questionnaire result data

The respondent's highest admiration towards the employees' disciplines on the category 'agree' is $45.2 \%$ followed by the abstain category $16.4 \%$, and the lowest level on the category 'very disagree' is $8.2 \%$.

\subsection{Motivation}

Motivation $\left(\mathrm{X}_{2}\right)$ is the incentive power making someone or organization being eager to exert the capabilities of expertness and skills, power and times to carry out various activities as his/her responsibilities for gaining the varied targets which have been determined before. The respondents' reply results on the motivation indicators are revealed in the following table below.

Table 3. The answer recapitulations of the employees' motivation

\begin{tabular}{c|c|c|c}
\hline No & Category & Frequency & Percentage \\
\hline 1 & Very agree & 24 & 32.9 \\
2 & Agree & 16 & 21.9 \\
3 & Abstain & 14 & 19.2 \\
4 & Disagree & 11 & 15.1 \\
5 & Very disagree & 8 & 10.9 \\
& TOTAL & 73 & 100 \\
\hline
\end{tabular}

Sources: Questionnaire result data 
The respondents' replies of the employees' highest motivation on the category 'very agree' is $32.9 \%$, it is followed by the category 'agree' $21.9 \%$, then it is followed by the abstain $19.2 \%$ and then the lowest category of 'very disagree' is 10.9 $\%$.

\subsection{Variable Impact Analyses}

In doing the aggressive analysis computing practically, all data are managed by using the application of computer of soft ware SPSS 22.0 for windows. From the computing results using the full regression model, the summary results are presented in the following table below.

Table 5. The Analysis Results of Multiple Linier Regression Coefficient

\begin{tabular}{c|c|c|c|c|c}
\hline & Un-standardized Coefficient & Standardized Coefficient & & \multirow{2}{*}{ T } & Significant \\
\hline Model & $\mathbf{B}$ & Standard Error & Beta & & \\
(Constant) & .696 & .393 & & 1.771 & .081 \\
$\mathbf{X}_{\mathbf{1}}$ & .254 & .051 & .365 & 4.991 & .000 \\
$\mathbf{X}_{\mathbf{2}}$ & .434 & .060 & .543 & 7.203 & .000 \\
$\mathbf{X}_{\mathbf{3}}$ & .248 & .069 & .266 & 3.581 & .001 \\
\hline
\end{tabular}

\section{Dependent variable: $Y$}

Based on the above management results, in the Table 7, Un-standardized Coefficient column, the multiple linier regression is obtained as follows:

\section{$Y=0.696+(0.254) X_{1}+(0.434) X_{2}+(0.248) X_{3}$}

In line with the above equation, it can be described that (1) the constant (a) $=0.696$ indicating the constant value, if the discipline variable $\mathrm{X}_{1}$, motivation $\mathrm{X}_{2}$, and leadership $\mathrm{X}_{3}=0$, the employees' performances of Makassar Lantamal office VI will increase 0.696 , (2) The coefficient $X_{1}(b 2)=0.434$, indicates that the discipline variable affects positively on the employees' performances of Makassar Lantamal office VII. In other words, If the discipline variable is increased one unit, the employees' performances of Makssar Lantamal office VI will develop 0.254, (3) The coefficient $X_{2} \quad(b 2)=0.434$, shows that the motivational variable influences positively the employees' performances at Makassar Lantamal ofiice VI. In other words, if the motivational variable is added to one unit, the employees' performances at Makassar Lantamal office $\mathrm{VI}$ will extend 0.434 , and (4) The coefficient $\mathrm{X}_{3}(\mathrm{~b} 3)=0.248$, displays that the leadership variable inspires the employees' performances of Makassar Lantamal office VI positively. In other words, if the leadership variable is built up one unit, the the employees' performances of Makassar Lantamal office VI will raise 0.248 .

\subsubsection{T-Test of Partial Significant Test}

\subsubsection{The t-test of partial significance}

The t-test aims at recognizing the big amount of impact of each independent variable individually towards the dependent variable. The test result of output SPSS can be read in the coefficient table above. The table 5 indicates that the discipline variable $X_{1}(a)$ The discipline variable $X_{1}$ influences positively and significantly the employees' performances of Makassar Lantamal office VI. This can be seen from the significant value $(0.000)$ under smaller value of 0.05 and the value of $t$ count $4.991>$ value of $t$ table 1.667. This implies that the employees' performances of Makassar Lantamal office VI happen well enough among them that make them increasing their working spirit. (b) The motivation variable $\left(\mathrm{X}_{2}\right)$ has an effect on the employees' performances of Makassar Lantamal office VI. This can be known from the substantial value (0.000) under the smaller value from 0.05 and the value of $t$ count $7.203>$ the value of $t$ table 1.667 . This means that the employees of Makassar Lantamal office $\mathrm{VI}$ feel satisfactorily with the organizational leadership who gives motivation that makes them increasing their working strength, and (c) the leadership variable $\left(X_{3}\right)$ impresses the employees' performances of Makassar Lantamal office VI positively and significantly. This case can be understood from the significant value (0.001) under smaller value of 0.05 and the value of $t_{\text {count }} 3.581>$ the value of $t$ table 1.667 . The research results present the availability of leadership influencing the employees' performances of Makassar Lantamal office VI. If this leadership is implemented continuously by the leader/manager, the employees' competence will improve. 


\subsubsection{Simultaneity Significant Test (F-Test)}

The F-test is used to test each independent variable consisting of motivation, discipline, and leadership have positive and significant imprint towards the dependent variable of employees' performances cooperatively. The value of $F$ count is to be obtained by using the assistance of software SPSS 22.0 for windows, then being compared with the value of $F$ table on the level of $\alpha=5 \%=2.164$ by the test criteria as follows in table 6 below.

Table 6: ANOVA

\begin{tabular}{l|c|c|c|c|c|}
\hline Model & Sum of Squares & Df & Mean Square & F & significance \\
\hline Regression & 9.840 & 3 & 3.280 & 41.331 & .000 \\
Residual & 5.476 & 69 & .079 & & \\
Total & 15.315 & 72 & & & \\
\hline a. Dependent Variable : $Y$ & & & \\
b. Predictor (Constant) $\left(\mathrm{X}_{3}\right),\left(\mathrm{X}_{1}\right)$, and $\left(\mathrm{X}_{2}\right)$ &
\end{tabular}

In the above table $6, F$ count is 41.331 with the significant level 0.000 . As a result, the computing indicates that $F$ count $>F$ table $(41.331>2.164)$ and its significant level $0.000<0.05$. This case shows that the independent variable consisting of discipline, motivation and leadership together clout the dependent variable of the employees' performances of Makassar Lantamal office VI positively and significantly.

\subsubsection{Determinant Coefficient Testing $\left(R_{2}\right)$}

The Determinant coefficient testing $\left(R_{2}\right)$ obviously measures how far model capabilities explain the dependent variable. The determinant coefficient is about between 0 (zero) to 1 (one) $=\left(0 \leq R_{2} \leq 1\right)$ if $R_{2}$ becomes bigger. Thus, it can be said that the influence of independent variable $(X)$ is as big as dependent variable $(Y)$. This means that the model being used is more powerful to explain the impact of independent variable on the dependent variable. On the other hands if $R_{2}$ becomes smaller to 0 (zero), it can be said that the effect of independent variable $\left(x_{1}, x_{2}\right.$ and $\left.x_{3}\right)$ towards the dependent variable $(Y)$ becomes smaller and smaller. Let's see the following table below.

Table 7. Model Summary of Determinant Coefficient

\begin{tabular}{l|c|c|c|c}
\hline Model & $\mathbf{R}$ & $\mathbf{R}$ Square & Adjusted R Square & Standard Error of the Estimate \\
\hline 1 & 802 & 642 & 627 & 28170 \\
\hline \multicolumn{6}{l}{} \\
\hline a. Predictors (Constant) $\mathrm{X}_{1}, \mathrm{X}_{2}$ and $\mathrm{x}_{3}$ \\
b. Dependent Variable : $\mathrm{Y}$
\end{tabular}

Based on the table 7 above, it is recognized that (a) $R=0.802$ implies that the relationship between the independent variable (discipline, motivation and leadership) towards the dependent variable $(Y)$ the employees' performances of Makassar Lantamal office VI is $80.2 \%$, this means their liaison is more accurate. The bigger the $\mathrm{R}$ value, the stronger their relationship.

Based on the table 7 above, it is recognized that (a) $R=0.802$ implies that the relationship between the independent variable (discipline, motivation and leadership) towards the dependent variable $(Y)$ the employees' performances of Makassar Lantamal office $\mathrm{VI}$ is $80.2 \%$, this means their liaison is more accurate. The bigger the R value, the stronger their relationship, (b) The R square is 0.642 means $64.2 \%$ of the employees' performances of Makassar Lantamal office VI can be explained by discipline, motivation and leadership Whilst its residual is $35.8 \%$ can be clarified by the factors that are not investigated in this research, and (c) The standard error of the estimation (deviation standard) is 0.28170 meaning the model is valued good because the smaller deviation standard becomes, the better model becomes.

Derived from the $F$ test of independent variable comprising discipline, motivation and leadership together impress the employees' performances of the dependent variable positively and significantly at Makassar Lantamal office VI. 


\section{Conclusions and Suggestions}

\subsection{Conclusions}

Discipline, motivation, and leadership impress the employees' performances at Makassar Lantamal office VI through either partially or simultaneously. This can be known from the significant value of partial regression coefficient ( $t$-test) and simultaneity test (f-test) that is smaller than the value of $\alpha=0.5 \%$. Motivation factor affects more strongly the employees' performances at Makassar Lantamal office VI.

\subsection{Suggestions}

To all employees of Makassar Lantamal office $\mathrm{VI}$ are expected to improve their performances in each duty. This can be done by habituating the high working discipline culture through the implementation of standard operating procedure (SOP) comprehensively based on the organization needs and conduct the best services to the institution and societies, and to the leader/manager of Makassar Lantamal office VI needs to supervise all employees' activities through either continuously or periodically, for instance, overnight inspection, and carries out the sanction which has been available according to the violation level, and gives reward to the employee who has high performances.

\section{References}

Brantas, (2009). Management bases. 1stedition. Publisher: Alfabeta, Bandung.

Cecep, D. (2003). Organization Behavior Management. Publisher: Prenada Media, Jakarta.

Davis, Gordon, (2004). Information system management. Publisher: TP. Midas Surya Grafindo, Jakarta.

Dessler, Gary, (2008). Human Resources Management. Prentice Hall, Inc.

Etykawaty (2008). Various kinds of manpower technique. 1 $1^{\text {st }}$ edition, Publisher: Bharata Karya Aksara, Jakarta.

Gibson, James, L. (2007). Organization, Management, Behavior, Structures and Process. Translation - Djoerban Wahid. Publisher: Erlangga, Jakarta

Hernowo (2008). Personel management and man sources. Publisher: BPFE Yogyakarta.

Hasibuan, Melayu SP., 2005. Mansources Management. Publisher: Bumi Aksara, Jakarta.

Herzberg, Frederick, B. Mausner, \& B. Snyderman.(1959). The Motivation to Work. New York: McGraw-Hill.

Mayo, Elton. (1933). The human problems of an industrial civilization. New York: Macmillan.

McClelland, David C. (1987). Human Motivation, Cambridge University Press, Cambridge.

Stoner, James A.F., (2006). Manajemen. Translation: Antarikso, et al. Publisher: Erlangga, Jakarta.

Taylor, Frederick. (1911). Scientific Management. New York: Harper publisher.

Vroom, V,H., \& Deci E.L. (1983). Management and Motivation, Penguin: Publisher 
